\title{
Publication rate of abstracts orally presented at the Turkish Society of Anaesthesiology and Reanimation National Congresses
}

\author{
Büşra Tok Ģekmecelioğlu ${ }^{1}$ (iD), Betül Kozanhan² (D), Gülay Eren ${ }^{3}$ (iD \\ ${ }^{1}$ Department of Anaesthesiology and Reanimation, Health Sciences University Sultan Abdulhamid Han Training and Research Hospital, İstanbul, Turkey \\ ${ }^{2}$ Department of Anaesthesiology and Reanimation, Health Sciences University Konya Training and Research Hospital, Konya, Turkey \\ ${ }^{3}$ Department of Anaesthesiology and Reanimation, Başkent University İstanbul Hospital, İstanbul, Turkey
}

ORCID IDs of the authors: B.T.C. 0000-0002-4049-6392; B.K. 0000-0002-5097-9291; G.E. 0000-0002-5365-3641.

Cite this article as: Tok Cekmecelioglu B, Kozanhan B, Eren G. Publication rate of abstracts orally presented at the Turkish Society of Anaesthesiology and Reanimation National Congresses. Turk J Anaesthesiol Reanim 2019; 47(2): 151-7.

\begin{abstract}
Objective: The most widely accepted parameter in evaluating the quality of research presented at scientific congresses is the success of publishing that research in a peer-reviewed journal. There are limited data in the literature about the publishing rates of abstracts orally presented at national congresses of the Turkish Society of Anaesthesiology and Reanimation (TARD) in scientific journals. The aim of the present study was to investigate the literary contribution of oral presentations at the TARD Congresses (TARK) and to present proposals for future congresses with detailed evaluation of the literature.
\end{abstract}

Methods: Overall, 319 orally presented abstracts at the TARK between October 2011 and October 2014 have been reviewed in the PubMed and Google Scholar databases. Abstracts were evaluated with respect to the institution of the principal author, type of research, publication status in scientific journal, type of publication, year of publication, rate of citation, order of authors and changes in title.

Results: The distributions of investigated papers were as follows: $73.1 \%$ clinical research, $21.9 \%$ experimental research, $2.5 \%$ case presentations and $2.5 \%$ survey studies. Moreover, $57.7 \%$ of the abstracts had authors from universities, $16 \%$ from research-training hospitals and $26.3 \%$ from mixed institutions. Further, $42.3 \%$ of the abstracts were published as articles in a scientific journal, $65.9 \%$ of the manuscripts were published in the Science Citation Index Expanded (SCIE) indexed, $8.1 \%$ in non-SCIE indexed international journals and $25.9 \%$ in national journals. There was no statistically significant difference between institution from which publications were sent and the index status of the journal $(p=0.068)$. The average publication time of the abstracts was $15.01 \pm 12.26$ months.

Conclusion: The publication rate of abstracts orally presented at the TARK between October 2011 and October 2014 is $42.3 \%$, which is in accordance with other international studies. This indicates that the reports in the congresses were assessed by the jury according to international selection criteria and meticulously scored. The majority of the abstracts were published in journals that are listed in SCIE, indicating a quantitative data regarding the scientific quality of research in anaesthesiology.

Keywords: Congress, manuscript, publication, research

\section{Introduction}

The scientific congresses are the environments where individuals share their scientific experiences with large masses, exchange their views on their studies and cooperate and develop new ideas for future studies (1, 2). Many researchers had the chance to re-evaluate their studies under favour of feedbacks they received in these meetings and they started new studies by benefiting from new ideas after these organisations. However, many presentations presented in scientific organisations are not published in peer-reviewed journals as a full-length article to contribute to the literature of medicine. The fact that a limited number of individuals can participate in the congresses makes it more difficult to access current developments in science (3). 
The parameter, which is most widely accepted in assessing the quality of studies presented in scientific congresses, is the success of relevant study in a peer-reviewed journal (4). Publication of oral presentations in peer-reviewed journals is one of the most objective criteria indicating that the study has been carried out with scientifically valid methods (5). For these reasons, the publishing rate of oral presentations, which have been presented in scientific congresses, after the organisation is considered as an indicator of the meeting's scientific quality, as well as a proof of objectivity and quality in presentation selection (1-7).

The Turkish Association of Anaesthesiology and Reanimation (TARD) is the anaesthesiology professional organisation with the highest number of members in Turkey. TARD Congresses (TARK) are the anaesthesiology congresses held annually and have the highest level of participation. However, there are few data on the publishing rate of oral presentations, which have been presented in the TARK, in scientific journals. The aim of this research was to meet the data deficiency in the literature, to investigate the contribution of oral presentations presented in the TARK to the literature and to offer suggestions by examining the published presentations in details.

\section{Methods}

In previous studies, since the duration between the presentation of a scientific study in a congress and the publication of that study was reported to be approximately 20 months (2), the 2014 Congress was accepted as the last year to be examined, and the statuses of all the oral presentations presented in the TARK between October 2011 and October 2014 were analysed by taking June 2017 as the final date. The presentations were obtained from the official webpage of the TARD (http://www.tard.org.tr/akademi/). In the present research designed as a retrospective study, the PubMed and Google Scholar databases were scanned. The title, names of all the authors (starting from the first author) and keywords were searched separately in Turkish and English languages. The presentations were evaluated from the aspects of the institution (e.g. university hospital and training and research hospital (TRH)), type of research (e.g. clinic, experimental, case study and survey), publishing in a scientific journal and if it was presented in a contest. All the presentations published were analysed in terms of type of the peer-reviewed journal (e.g. Science Citation Index Expanded (SCIE), international journals out of the scope of SCIE and national journals) publishing year, duration between presentation and publishing, number of citations, changes in the order of authors and changes in the title.

While investigating the status of the publication, the initial letters of the first author's name and surname, the full title of the manuscript and a keyword were scanned at first. When no manuscript fitting the criteria could be found, then the scanning procedure was repeated for each of the next authors and keywords. If no study could be found despite previous procedures, another keyword related to the title was used together with the names of all the authors. If an abstract, study design and author name fitting the criteria could be found, and the accessed abstract or full text was matched with the abstract or full text of the presentation, then the title, month and year of the journal publishing the manuscript were recorded.

This research was conducted in accordance with the Declaration of Helsinki.

\section{Statistical analyses}

Statistical analyses were performed using IBM Statistical Package for the Social Sciences version 20 (IBMS SPSS Statistics Corp.; Armonk, NY, USA). The analyses of non-normally distributed data were performed using the Kruskal-Wallis test. Categorical variables were analysed using the chi-square test. Numerical variables were expressed as mean and standard deviation, whereas categorical variables were expressed as percentage. The results were analysed at a 95\% confidence level. A p value $<0.05$ was accepted as statistically significant.

\section{Results}

Of the 319 oral presentations examined in the present study, $73.1 \%$ were clinical research, $21.9 \%$ experimental study, $2.5 \%$ survey and $2.5 \%$ case study (Table 1 ). Of the 319 presentations, $75.2 \%$ were accepted for presentation in oral presentation sessions, whereas $24.8 \%$ were accepted to be the best clinical or experimental research in event sessions. When the accepted oral presentations were analysed from the aspects of the submitter's institution, $57.7 \%$ of the presentations were found to be submitted from university hospitals, 16\% from TRHs and $26.3 \%$ by the authors from different institutions.

Of the presentations, $136(42.3 \%)$ were published as an article in a scientific journal. When the presentations were examined by years, $46.3 \%$ of the presentations of the year $2011,40 \%$ of the presentations of the year $2012,40 \%$ of the presentations of the year 2013 and $44.3 \%$ of the presentations of the year 2014 were published. There was no statistically significant difference between the publishing rates of presentations by year $(p=0.808)$ (Table 1$)$. When examined from the aspect of the institution, $42.9 \%$ of the presentations submitted from university hospitals, 31.4\% of the presentations submitted from TRHs and $50 \%$ of the presentations submitted by authors from different types of institutions were published, and there was no statistically significant difference in terms of publishing in a scientific journal $(\mathrm{p}=0.080)$ (Table 1$)$. 


\begin{tabular}{|c|c|c|c|c|}
\hline & $\begin{array}{c}\text { Number of published } \\
\text { presentations, } \mathbf{n}(\%)\end{array}$ & $\begin{array}{l}\text { Number of unpublished } \\
\text { presentations, } \mathbf{n}(\%)\end{array}$ & \begin{tabular}{|c|} 
Total number of \\
presentations, $\mathbf{n}(\%)$
\end{tabular} & $\mathbf{p}$ \\
\hline \multicolumn{5}{|l|}{ Publication Year } \\
\hline 2011 & $37(46.3)$ & $43(53.7)$ & $80(100)$ & 0.8 \\
\hline 2012 & $32(40)$ & $48(60)$ & $80(100)$ & \\
\hline 2013 & $32(40)$ & $48(60)$ & $80(100)$ & \\
\hline 2014 & $35(44.3)$ & $44(55.7)$ & $79(100)$ & \\
\hline \multicolumn{5}{|l|}{ Type of study } \\
\hline Case report & $3(37.5)$ & $5(62.5)$ & $8(100)$ & 0.51 \\
\hline Research article & $94(40.3)$ & $139(59.7)$ & $233(100)$ & \\
\hline Experimental study & $35(50)$ & $35(50)$ & $70(100)$ & \\
\hline Survey study & $4(50)$ & $4(50)$ & $8(100)$ & \\
\hline \multicolumn{5}{|l|}{ Institution } \\
\hline Research and teaching hospital & $16(32)$ & $34(68)$ & $50(100)$ & 0.14 \\
\hline University & $79(42.9)$ & $105(57.1)$ & $184(100)$ & \\
\hline Private hospital & $41(48.3)$ & $44(51.7)$ & $85(100)$ & \\
\hline
\end{tabular}

Table 2. Published article distribution in anesthesiology-algology-intensive care journals those searched under SGI-E

\begin{tabular}{|l|c|}
\hline Name of the Journal & Number \\
\hline Revista Brasileira de Anestesiologia & 9 \\
Pediatric Anesthesia & 3 \\
European Journal of Anaesthesiology & 3 \\
BMC Anesthesiology & 2 \\
Journal of Clinical Anaesthesia & 1 \\
Journal of Anesthesia & 3 \\
Journal of Cardiothoracic and Vascular Anesthesia & 1 \\
ACTA Anaesthesiologica Belgica & 1 \\
Anaesthesia and Intensive Care & 1 \\
Anaesthesia & 1 \\
Annals of Intensive Care & 1 \\
Clinical Journal of Pain & 1 \\
Minerva Anestesiologica & 1 \\
Pain Research and Management & 31 \\
Total & \\
\hline
\end{tabular}

Of the published articles, $90(66.1 \%)$ were published in journals indexed by SCIE, $11(8.1 \%)$ in an international journal not indexed by SCIE and 35 (25.9\%) in a national journal. The preferences of authors for the journals indexed in SCIE and focusing on anaesthesia, intensive care and pain are presented in Table 2. The distribution of articles published in journals of other disciplines is presented in Table 3. The authors' leading non-SCIE national and international journal preferences are the Turkish Journal of Anaesthesiology and Reanimation (7.3\%) and Agri (4.4\%).

When analysing the citation rates of the published articles by year, $70.3 \%$ of the presentations of the year $2011,81.3 \%$ of the presentations of the year 2012, 59.4\% of the presentations of the year 2013 and $48.6 \%$ of the presentations of the year 2014 were found to be cited, and the difference was found to be statistically significant $(\mathrm{p}=0.03)$. When analysing the citation rates of the published articles by the submitter's institution, the citation rate of university-centred articles was found to be $65.8 \%$, that of articles submitted from TRH was $62.5 \%$ and the citation rate of articles submitted by the authors from different types of institution was $63.4 \%$; the difference was not found to be statistically significant $(\mathrm{p}=0.948)$.

Moreover, $45.6 \%$ of the presentations presented in contest and $41.7 \%$ of those not presented were published, and the difference between them was not found to be statistically significant $(p=0.543)$. The detailed analysis of the process of the published articles from the presentation in congress to the publication is presented in Table 4 . In the publishing process of the presented texts, the parameters of change were determined to be in the title change, change in number and order of authors and change of the first author, and the rates of change were calculated. The rate of publishing without any change was found to be $24.3 \%$. The parameter with the highest rate of change was determined to be the title with a $10.3 \%$ change.

The mean duration of publishing in a scientific journal was found to be $15.01 \pm 12.26$ months for the published presentations, which have been presented in a congress. When ex- 
Table 3. Distribution of manuscripts published in other disciplinary journals searched under SGI-E

\begin{tabular}{|c|c|}
\hline Name of the Journal & Number \\
\hline Turkish Journal of Medical Sciences & 6 \\
\hline Journal of Clinical Monitoring and Computing & 4 \\
\hline Pakistan Journal of Medical Science & 4 \\
\hline $\begin{array}{l}\text { European Review for Medical and } \\
\text { Pharmacological Sciences }\end{array}$ & 4 \\
\hline $\begin{array}{l}\text { International Journal of Clinical and } \\
\text { Experimental Medicine }\end{array}$ & 3 \\
\hline Bratislava Medical Journal & 2 \\
\hline International Journal of Surgery & 2 \\
\hline Libyan Journal of Medicine & 2 \\
\hline Turkish Neurosurgery & 2 \\
\hline ACTA Biochimica Polonica & 1 \\
\hline Acta Medica Mediterranea & 1 \\
\hline Acta Neurochirurgica & 1 \\
\hline African Health Sciences & 1 \\
\hline Archives of Medical Science & 1 \\
\hline $\begin{array}{l}\text { Biomedical Papers of the Medical Faculty } \\
\text { of the University Palacky }\end{array}$ & 1 \\
\hline Biomedical Research International & 1 \\
\hline Bratislavske Lekarske Listy & 1 \\
\hline Chinese Medical Journal & 1 \\
\hline Current Therapeutic Research & 1 \\
\hline $\begin{array}{l}\text { European Journal of Obstetrics \& Gynecology and } \\
\text { Reproductive Biology }\end{array}$ & 1 \\
\hline Experimental Animals & 1 \\
\hline Heart Surgery Forum & 1 \\
\hline Indian Journal of Medical Research & 1 \\
\hline International Wound Journal & 1 \\
\hline $\begin{array}{l}\text { Journal for Oto-Rhino-Laryngology, Head and } \\
\text { Neck Surgery }\end{array}$ & 1 \\
\hline Journal of International Medical Research & 1 \\
\hline Journal of Investigative Surgery & 1 \\
\hline Journal of Research in Medical Sciences & 1 \\
\hline Libyan Journal of Medicine & 1 \\
\hline Medical Science Monitor & 1 \\
\hline Neurosciences & 1 \\
\hline Ultrastructural Pathology & 1 \\
\hline Renal Failure & 1 \\
\hline Surgical and Radiologic Anatomy & 1 \\
\hline The Journal of Craniofacial Surgery & 1 \\
\hline The Journal of Minimally Invasive Gynecology & 1 \\
\hline The Journal of The Society For Simulation in Healthcare & 1 \\
\hline The Korean Journal of Physiology and Pharmacology & 1 \\
\hline Transplantation Proceedings & 1 \\
\hline Total & 59 \\
\hline
\end{tabular}

amining the institution of authors submitting the publication, the presentations submitted from a university were found to be published in $15.37 \pm 12.25$ months, those submitted from a TRH in $16.43 \pm 11.35$ months and those submitted by authors from different types of institution in $13.75 \pm 12.81$ months. There was no statistically significant difference between the institutions in terms of publishing durations of presentations $(\mathrm{p}=0.59)$.

\section{Discussion}

The aim of the present study was to examine the oral presentations presented in the TARK between 2011 and 2014 in detail and to investigate their contribution to the literature. The oral presentations presented in the TARK between October 2011 and October 2014 were published in scientific journals at similar rates, and there was no statistically significant difference between the rate of publishing in peer-reviewed scientific journals. Moreover, most of the journals, in which the oral presentations presented in the TARK were published, were found to be indexed in SCIE.

There are many studies examining the publishing rates of presentations presented in scientific meetings and congresses in different disciplines $(1,2)$. In a Cochrane review published by Scherer et al. (3) in 2007, the publishing rates of presentations presented in a congress show a very wide range, and the mean percentage was found to be $44 \%$. In their review, there are many studies from different disciplines. Although there are few studies on the publishing rates of congress presentations on anaesthesiology and reanimation, studies are similar to those in other medical disciplines. In the study by Meranze et al. (8) in 1982, the publishing rate of presentations presented in Congress 1978 of the American Society of Anesthesiologists (ASA) and Congress 1979 and Congress 1980 of the International Anesthesia Research Society (IARS) was found to be $33.8 \%$. In 1993, the congresses of four different anaesthesia associations (ASA, IARS, Anesthesia Research Society and Canadian Anesthesiologists' Society Meetings) held in 1985 were examined, and the rate of publishing in the first 3 years was reported to be $44 \%$, and the rate of publishing in the first 5 years was reported to be $50 \%$. There was no statistically significant difference between the publishing rates of presentations presented in congresses (9). In our recent literature review, in the year 2017, Gerlach et al. (10) analysed the presentations presented in Congresses of the Society for Obstetric Anesthesia and Perinatology between 2010 and 2014. According to their study, the publishing rate of those studies was found to be $26.8 \%$. In the present study, the publishing rate was found to be similar to this percentage, and the timing distribution of summary presentations presented in the TARKs showed parallelism with the studies in 2-3 years and before. The fact that $<5$ years passed from the congresses in 


\begin{tabular}{|c|c|c|c|c|c|}
\hline & \multicolumn{4}{|c|}{ Publication Year } & \multirow[b]{2}{*}{ Total } \\
\hline & 2011 & 2012 & 2013 & 2014 & \\
\hline No change in the manuscript & 4 & 1 & 7 & 21 & 33 \\
\hline 1) Order of authors & 3 & 1 & 9 & 0 & 13 \\
\hline 2) Author count & 1 & 1 & 1 & 1 & 4 \\
\hline 3) Change in the title & 3 & 3 & 2 & 6 & 14 \\
\hline 4) Name change in the first author & 0 & 0 & 0 & 0 & 0 \\
\hline 5) 1 and 2 together & 5 & 0 & 3 & 5 & 13 \\
\hline 6) 1,2,3 together & 10 & 1 & 2 & 1 & 14 \\
\hline 7) 1 and 3 together & 0 & 2 & 1 & 1 & 4 \\
\hline 8) $1,2,3,4$ together & 3 & 8 & 0 & 0 & 11 \\
\hline 9) 1 and 4 together & 4 & 4 & 3 & 0 & 11 \\
\hline 10) $1,3,4$ together & 1 & 9 & 2 & 0 & 12 \\
\hline 11) 1,2, 4 together & 3 & 2 & 2 & 0 & 7 \\
\hline Total & 37 & 32 & 32 & 35 & 136 \\
\hline
\end{tabular}

2013 and 2014 suggests that an increase might occur in the next reviews.

In their study on the publishing rate of presentations presented in the National Congresses of the Turkish Association of Anaesthesiology and Reanimation, Erkal et al. (11) reported the publishing rate of oral presentations to be $12.8 \%$. In the present study, the publishing rates of oral presentations were found to be $42.1 \%$ for the same years and $42.3 \%$ for the years between 2011 and 2014. We believe that the difference emerges because Erkal et al. used only the names of the first and second authors together with the title of the study as the scanning criteria. The higher publishing rate found in the present study might arise from the scanning procedure performed by using the names of all the authors and also all the keywords in the same databases (PubMed and Google Scholar). Since the scanning method yielded a significant difference, this method would shed light to future studies.

There are many studies examining the presentations presented in national congresses in disciplines other than anaesthesiology and reanimation $(6,12-15)$. In these studies, the publishing rates of oral presentations presented in national congresses were found to be $15 \%$ for radiology (6), $32 \%$ for rheumatology (12), 30\% for plastic surgery (13), $21 \%$ for thoracic surgery (14) and $4.3 \%$ for general surgery (15). The publishing rates of oral presentations presented in the TARK are higher than the publishing rates of other disciplines, and they show similarity with the international data. The most important finding obtained in the present study was that $42.3 \%$ of the oral presentations presented in the TARK were published in a peer-reviewed journal. This finding corroborates the Cochrane review by Scherer et al. (3) published in 2007 on examining different disciplines from medicine. The similarity of this rate with the literature suggests that the oral presentations presented in the TARK were evaluated carefully in accordance with the international selection criteria. Moreover, it is a quantitative data on the scientific quality of studies in the discipline of anaesthesiology and reanimation that most of the journals, in which the oral presentations presented in the TARK were published, were indexed by SCIE.

The citation rates of published articles showed a statistically significant increase from the newer studies to the older ones. This is directly proportional to the availability to the researchers by being published in the literature.

There was no statistically significant difference between the submitter's institution and the publishing rate. This parallelism indicates that the oral presentations were objectively assessed in congresses.

The quantitative superiority and the increasing tendency of experimental studies, which have higher publishing rate than clinical studies do, can be explained with the quality of experimental procedure and data reporting. These researches require careful and experimental design, and it is planned to achieve important results; thus, it is more likely to improve them in a full-text article.

Even though any change in a scientific research draws attention, the authors may make a change before the acceptance of the manuscript in order to improve the efficiency of research, or these changes may be suggested by the referees (e.g. changing the title or re-structuring the abstract). In most of the articles, it was observed that the changes were made when compared with the abstract submitted to the congress, and this applies to the other national congresses (16). The title was 
changed in $11 \%$ of the published abstracts. This rate is lower than the values reported previously (1). The changes in author names and order were found to be in parallel with the study by Yalçınkaya and Bagatur $(1,16)$. As discussed above, the presentations presented in congresses may be the preliminary studies. Particularly, national meetings are very important opportunities in order for young researchers to present their studies and for experienced researchers to achieve scientific feedback. From this perspective, we think that the differences and changes between oral presentations presented in congresses and articles published from these preliminary studies should be considered normal.

In their study in 2009 on examining the presentations presented in the International Commission on Occupational Health, Rollin et al. (17) reported that $18 \%$ of the presentations presented in congresses have been published before the congress. In the present study, this ratio was found to be only $5 \%$. This indicates that the feedbacks achieved in congresses are important for preparing the manuscripts.

In general, more than half of all the presentations are published as full-text articles after being presented in scientific organisations (3). In their study comparing the abstracts of studies on orthopaedics, which have not been published in 5 years from a specific meeting, Sprague et al. (18) determined that approximately $36 \%$ of the participants have not submitted their abstracts to any journal. In the survey conducted, the reasons were specified as follows: (1) insufficient research material available, (2) continuing research, (3) delay in writing the manuscript, (4) problems with co-authors and (5) deprioritisation of the research topic. According to Congress 2008 of the Société Française de Médecine Physique ve de Réadaptation (French Association of Physical Medicine and Rehabilitation), the three main factors limiting the publications are time deficiency, fear from rejection and nature of the preliminary study presented in congress (19). In general, an author should make an active effort for publishing his/her study. Thus, the rate of publishing after the presentation in congress represents the motivation of the author better than the quality of the article. For this reason, the scientific association and societies should encourage and motivate the authors of presentations, which have been accepted for the congress, to submit their manuscripts for publication in the scientific journal.

The scientific societies should prioritise the strategies towards increasing the publishing rate of presentations presented in congresses. The strategy of the European Association for Cardio-Thoracic Surgery can be given as an example. This association receives the preliminary acceptance for the publication of all the presentations, which are accepted for oral presentation, as an article in the European Journal of Car-
dio-Thoracic Surgery. There is an option for rapidly assessing the abstracts of presentations, which are accepted for oral presentation, and the final date of submission to the journal is determined before the congress.

The present study has also certain limitations. As stated in the methodology, the presentations were scanned in the Google Scholar and PubMed databases. The percentages might have been underestimated because the articles published and indexed in different databases have not been accessed. The poster presentations presented in the TARKs were not involved in the present study. Since there are fewer studies on this subject in anaesthesia discipline, the comparisons were made generally to the other disciplines.

\section{Conclusion}

Future studies should examine the factors related to non-publishing the presentations presented in the future anaesthesiology and reanimation congresses, as well as discussing the potential interventions in order to improve the rate of publishing. The surveys to be conducted on this subject might shed light for future studies.

\section{Peer-review: Externally peer-reviewed.}

Author Contributions: Concept - B.K.; Design - B.K.; Supervision - G.E.; Resources - B.T.C..; Data Collection and/or Processing - B.T.C..; Analysis and/or Interpretation - B.T.C..; Literature Search - B.K., G.E.; Writing Manuscript - B.T.Ç.; Critical Review - B.K., G.E.

Acknowledgements: We would like to thank Dr. Ibrahim Solak for his assistance with the statistical data used in this manuscript.

Conflict of interest: The authors declare that they have no conflicts of interest.

Financial disclosure: The authors declare that this study has received no financial support.

\section{References}

1. Bhandari M, Devereaux PJ, Guyatt GH, Cook DJ, Swiontkowski MF, Sprague S, et al. An observational study of orthopaedic abstracts and subsequent full-text publications. J Bone Joint Surg Am 2002; 84-A: 615-21.

2. Von Elm E, Costanza MC, Walder B, Tramèr MR. More insight into the fate of biomedical meeting abstracts: a systematic review. BMC Med Res Methodol 2003; 3: 12. [CrossRef]

3. Scherer RW, Langenberg P, Von Elm E. Full publication of results initially presented in abstracts. Cochrane Database Syst Rev 2007; 2: MR000005.

4. Schulte TL, Trost M, Osada N, Huck K, Lange T, Gosheger G, et al. Publication rate of abstracts presented at the Annual Con- 
gress of the German Society of Orthopaedics and Trauma Surgery. Arch Orthop Trauma Surg 2012; 132: 271-80. [CrossRef]

5. Uniform Requirements for Manuscripts Submitted to Biomedical Journals. JAMA Netw Open 1997; 277: 927-34.

6. Seçil M, Uçar G, Sentürk Ç, Karasu S, Dicle O. Publication rates of scientific presentations in Turkish national radiology congresses. Diagn Interv Radiol 2005; 11: 69-73.

7. Stolk P, Egberts ACG, Leufkens HGM. Fate of abstracts presented at five International Conferences on Pharmacoepidemiology (ICPE): 1995-1999. Pharmacoepidemiol Drug Saf 2002; 11: 105-11. [CrossRef]

8. Meranze J, Ellison N, Greenhow DE. Publications resulting from anesthesia meeting abstracts. Anesth Analg 1982; 61: 4458. [CrossRef]

9. Yentis SM, Campbell FA, Lerman J. Publication of abstracts presented at anaesthesia meetings. Can J Anaesth 1993; 40: 632-4. [CrossRef]

10. Gerlach B, Shah AM, Lee MT, Wong CA, Sullivan JT, Toledo P. Publication rate of abstracts presented at the society for obstetric anesthesia and perinatology annual meetings 20102014. Anesth Analg 2017; 124: 887-9. [CrossRef]

11. Erkal KH, Yuce Y. Publication rate of abstracts presented in national congress of Turkish society of anesthesiology. J Clin Anal Med 2018; 9: 195-9.

12. Kalyoncu U, Çınar M, Demirağ MD, Yılmaz S, Erdem H, Kiraz S, et al. Ulusal Romatoloji Kongrelerinde sunulan bildirilerin irdelenmesi: Neredeyiz?. RAED Dergisi 201 1; 3: 6-10.

13. Ersoy B. What is the Ultimate Fate of Presented Abstracts? Conversion Rates of Presentations to International Publica- tions from the 31 st National Congress of Plastic, Reconstructive, and Aesthetic Surgery. TurkJ Plast Surg 2016; 24: 1.

14. Evman S, Akyıl M, Tezel Ç, Kanbur S, Misırlığlu A, Akyıl F, et al. What fate befalls the congress proceedings? Conversion rates of National Thoracic Surgery Congress proceedings into international publications. Turk Gogus Kalp Dama 2017; 25: 249-54. [CrossRef]

15. Kabay B, Teke Z, Erbiş H, Koçbil G, Tekin K, Erdem, E. Ulusal Cerrahi Kongrelerinde sunulan bildirilerin uluslararası yayına dönüşme oranları. Turk J Surg 2005; 21: 130-4.

16. Yalçınkaya M, Bagatur E. Fate of abstracts presented at a National Turkish Orthopedics and Traumatology Congress: publication rates and consistency of abstracts compared with their subsequent full-text publications. Acta Orthop Traumatol Turc 2013; 47: 223-30. [CrossRef]

17. Rollin L, Darmoni S, Caillard JF, Gehanno JF. Fate of abstracts presented at an International Commission on Occupational Health (ICOH) congress-followed by publication in peer-reviewed journals? Scand J Work Environ Health 2009; 35: 4615.

18. Sprague S, Bhandari M, Devereaux PJ, Swiontkowski MF, Tornetta III P, Cook DJ, et al. Barriers to full-text publication following presentation of abstracts at annual orthopaedic meetings. J Bone Joint Surg Am 2003; 85: 158-63. [CrossRef]

19. Allart E, Beaucamp F, Tiffreau V, Thevenon A. Fate of abstracts presented at the 2008 European Congress of Physical and Rehabilitation Medicine. Eur J Phys Rehabil Med 2015; 51: 469-75. 